\title{
Adubação nitrogenada de sorgo granífero consorciado com capim em sistema de plantio direto
}

\author{
Gustavo Pavan Mateus ${ }^{(1)}$, Carlos Alexandre Costa Crusciol(2), Émerson Borghi( ${ }^{(3)}$, \\ Cristiano Magalhães Pariz ${ }^{(4)}$, Ciniro Costa $^{(5)}$ e João Paulo Franco da Silveira ${ }^{(4)}$
}

\begin{abstract}
(1)Agência Paulista de Tecnologia dos Agronegócios, Polo Regional de Desenvolvimento Tecnológico dos Agronegócios do Extremo Oeste, Caixa Postal 67, CEP 16900-000 Andradina, SP. E-mail: gpmateus@apta.sp.gov.br (2)Universidade Estadual Paulista (Unesp), Faculdade de Ciências Agronômicas, Departamento de Produção Vegetal, Caixa Postal 237, CEP 18603-970 Botucatu, SP. E-mail: crusciol@fca.unesp.br (3)Embrapa Pesca e Aquicultura, Quadra 103 Norte, Conjunto 01, Lote 17, Térreo CEP 77015-012 Palmas, TO. E-mail: emerson.borghi@embrapa.br (4)Unesp, Faculdade de Medicina Veterinária e Zootecnia, Programa de Pós-Graduação em Zootecnia, Caixa Postal 560. CEP 18618-000 Botucatu, SP. E-mail: cmpzoo@gmail.com, joaopaulo_franco@ig.com.br ${ }^{(5)}$ Unesp, Faculdade de Medicina Veterinária e Zootecnia, Departamento de Melhoramento e Nutrição Animal, Caixa Postal 560. CEP 18618-000 Botucatu, SP. E-mail: ciniro@fmvz.unesp.br
\end{abstract}

Resumo - O objetivo deste trabalho foi avaliar o efeito do manejo da adubação nitrogenada sobre a cultura do sorgo granífero, cultivado solteiro e em consócio com capim-marandu e capim-mombaça, e determinar a produtividade de matéria seca das forrageiras, nos anos agrícolas 2003/2004 e 2004/2005, em plantio direto. Foi utilizado o delineamento experimental em blocos ao acaso, em arranjo fatorial $3 \times 5$, com quatro repetições. Os tratamentos consistiram de três sistemas de cultivo de sorgo granífero (solteiro e consorciado com capim-marandu ou capim-mombaça, na linha de semeadura) e cinco manejos de adubação nitrogenada: 30-70; 70-30; 50-50; 100-0; e 0-100 $\mathrm{kg} \mathrm{ha}^{-1}$ de $\mathrm{N}$, quantidades aplicadas na semeadura e na cobertura, respectivamente. $\mathrm{O}$ cultivo consorciado não afetou a nutrição nem a produtividade de grãos de sorgo. Apenas no primeiro ano de cultivo, o parcelamento 50-50 $\mathrm{kg} \mathrm{ha}^{-1}$ de $\mathrm{N}$ proporcionou maior produtividade de grãos. O manejo da palhada interferiu no estabelecimento do sorgo no segundo ano de cultivo, e diminuiu a produtividade de grãos. As maiores doses de $\mathrm{N}$ aplicadas em cobertura elevaram a produtividade de matéria seca do capim-marandu e, as aplicadas em semeadura, a elevaram no capim-mombaça.

Termos para indexação: Panicum maximum, Urochloa brizantha, integração lavoura-pecuária, produtividade de grãos, teor foliar.

\section{Nitrogen fertilization on sorghum intercropped with grass in a no-tillage system}

\begin{abstract}
The objective of this work was to evaluate the effect of nitrogen fertilization management on single and intercropped sorghum with Marandu and Mombaça grasses, and to determine the forage dry weight yield in the 2003/2004 and 2004/2005, in a no-tillage system. The experimental design was in randomized block, in a $3 \times 5$ factorial arrangement, with four replicates. The treatments consisted of three sorghum cropping systems (single and intercropped with Marandu and Mombaça grasses in the rows) and five nitrogen fertilizer managements: $30-70 ; 70-30 ; 50-50 ; 100-0$; and $0-100 \mathrm{~kg} \mathrm{ha}^{-1}$ of $\mathrm{N}$, applied at sowing and topdressing, respectively. Intercropping did not affect sorghum nutrition nor grain yield. Only in the first growth season, the $50-50 \mathrm{~kg} \mathrm{ha}^{-1}$ of N splitting increased grain yield. Straw management interfered in sorghum establishment during the second growth season and decreased grain yield. The highest rates of $\mathrm{N}$ topdressing increased forage dry weight yield of Marandu grass and, applied at sowing, $\mathrm{N}$ highest rates increased this attribute in Mombaça grass.
\end{abstract}

Index terms: Panicum maximum, Urochloa brizantha, crop-livestock integration system, grain yield, leaf content.

\section{Introdução}

Entre as tecnologias agrícolas para recuperação de áreas degradadas, a redução dos custos de produção e o uso intensivo da área, principalmente sob lavoura durante todo o ano, destaca-se a integração lavoura-pecuária em sistema plantio direto(SPD) (Macedo, 2009). No entanto, sua adoção é altamente dependente da produção de forragem na entressafra e da manutenção de palhada sobre a superfície do solo; atualmente, as culturas mais promissoras nesse sistema são: soja, milho, milheto, sorgo granífero ou forrageiro e gramíneas forrageiras, consorciadas ou não, sobretudo as dos gêneros Panicum e Urochloa (Syn. Brachiaria).

Pesq. agropec. bras., Brasília, v.46, n.10, p.1161-1169, out. 2011 
Além disso, em razão dos grandes investimentos para a formação, recuperação e reforma de pastagens, têm-se buscado diversas estratégias para diminuir esses investimentos (Jakelaitis et al., 2005). Assim, a integração lavoura-pecuária tem se tornado opção vantajosa e beneficiado duas atividades de importância econômica, o que proporciona ganhos mútuos ao produtor. Para promover inovações tecnológicas das atividades agrícolas, tal sistema tem sido objeto de estudo em diversas regiões do mundo (Allen et al., 2007; Tracy \& Zhang, 2008; Balbinot Júnior et al., 2009; Carvalho et al., 2010).

$\mathrm{Na}$ integração lavoura-pecuária, o consórcio de capim dos gêneros Urochloa e Panicum com culturas graníferas como milho, soja, arroz, feijão e sorgo, pode ser realizado simultaneamente na mesma linha de semeadura, misturando-se a semente forrageira ao fertilizante, conforme Kluthcouski et al. (2000), com o objetivo de fornecer forragem para a alimentação animal, durante o período de baixa disponibilidade e, posteriormente, a formação de palhada para a continuidade do SPD.

Kluthcouski et al. (2000) avaliaram o comportamento da cultura do sorgo em consórcio com Urochloa brizantha (Hochst. ex A. Rich.) R.D. Webster, sob SPD, e verificaram redução na produtividade de grãos inferior a 2\%, em comparação ao cultivo solteiro. Essa redução pode atingir $10 \%$ e pode ser atribuída, em parte, à competição por nutrientes, principalmente nitrogênio $(\mathrm{N})$, pois as espécies consorciadas, nesse caso, são gramíneas, e o nutriente em questão é o mais extraído e o mais limitante à produção dessas espécies.

$\mathrm{Na}$ cultura do sorgo granífero, o acúmulo de $\mathrm{N}$ ocorre quase linearmente até a maturação. Rosolem et al. (1985) demonstraram a responsividade do sorgo granífero à adubação nitrogenada. No entanto, essa resposta é muito variável e está condicionada principalmente ao material genético, à produtividade, ao teor de matéria orgânica (MO) do solo e à disponibilidade hídrica para a cultura.

Estudos sobre o manejo da adubação nitrogenada sobre a cultura granífera e o comportamento da forrageira, no cultivo consorciado em SPD, são pouco explorados na literatura.

O objetivo deste trabalho foi avaliar o efeito do manejo da adubação nitrogenada na cultura do sorgo [Sorghum bicolor (L.)] granífero em cultivo solteiro e consorciado com os capins Marandu ou Mombaça, em $\mathrm{SPD}$, e a posterior produtividade de massa seca das forrageiras.

\section{Material e Métodos}

O experimento foi realizado nos anos agrícolas de 2003/2004 e 2004/2005, na Fazenda Experimental Lageado, pertencente à Faculdade de Ciências Agronômicas/Unesp, Campus de Botucatu, SP, a 22 ${ }^{\circ} 51^{\prime}$ S e $48^{\circ} 23^{\prime} \mathrm{W}$, com altitude de $765 \mathrm{~m}$. O clima, conforme a classificação de Köppen, é do tipo Cwa, tropical de altitude com inverno seco e verão quente e chuvoso.

$\mathrm{O}$ solo da área experimental foi classificado como Latossolo Vermelho distrófico (Santos et al., 2006), manejado durante seis anos em SPD: milho/ aveia-preta, 1997/1998;soja/milho safrinha, 1998/1999; milho/aveia-preta, 1999/2000; soja/aveia-preta, 2000/2001; milho/aveia-preta, 2001/2002; milho/ braquiária/milheto, 2002/2003. Os atributos químicos, antes da instalação do experimento, na camada do solo de 0 a $0,20 \mathrm{~m}$, foram: $4,8 \mathrm{pH}\left(\mathrm{CaCl}_{2}\right) ; 23 \mathrm{~g} \mathrm{~kg}^{-1}, \mathrm{MO}$; $19 \mathrm{mg} \mathrm{dm}^{-3}, \mathrm{P}$ (resina); $1,8 \mathrm{mmol}_{\mathrm{c}} \mathrm{dm}^{-3}, \mathrm{~K} ; 19 \mathrm{mmol}_{\mathrm{c}} \mathrm{dm}^{-3}$, $\mathrm{Ca} ; 13 \mathrm{mmol}_{\mathrm{c}} \mathrm{dm}^{-3}, \mathrm{Mg} ; 55 \mathrm{mmol}_{\mathrm{c}} \mathrm{dm}^{-3}, \mathrm{H}+\mathrm{Al}$; e $38 \%$ de saturação por bases (V).

Utilizou-se o delineamento experimental de blocos ao acaso, em arranjo fatorial $3 \times 5$, com quatro repetições. Os tratamentos constituíram-se de: três sistemas de cultivo do sorgo granífero híbrido P8118 - solteiro ou consorciado na linha de semeadura com Urochloa brizantha cv. Marandu e Panicum maximum cv. Mombaça; e cinco manejos (parcelamento) da adubação nitrogenada: 30 e 70; 70 e 30; 50 e 50; 100 e $0 ; 0$ e $100 \mathrm{~kg} \mathrm{ha}^{-1}$ de $\mathrm{N}$, respectivamente - quantidades aplicadas na semeadura e na cobertura, respectivamente - na forma de ureia. Cada parcela foi constituída por dez linhas de $10 \mathrm{~m}$ de comprimento, espaçadas em 0,45 m, com área total de $45 \mathrm{~m}^{2}$. Para as avaliações, foram consideradas as oito linhas centrais, tendo-se desprezado $1 \mathrm{~m}$ da extremidade de cada linha.

Em razão dos resultados da análise de fertilidade do solo, realizou-se a calagem superficial, em 15/10/2003, sobre o resíduo vegetal remanescente na área, com a dose de $4 \mathrm{Mg} \mathrm{ha}^{-1}$ de calcário dolomítico $($ PRNT $=72 \%)$, com o objetivo de elevar a V a $70 \%$, de acordo com as recomendações de Cantarella et al. (1997), para a cultura do sorgo granífero.

A semeadura do sorgo granífero solteiro e em consórcio com capim, nos dois anos agrícolas, foi realizada em 14/1/2004 e 23/11/2004, por meio de semeadora de semeadura direta, para atingir população de aproximadamente 200 mil plantas por hectare. Para o capim-marandu e o capim-mombaça, 
adotou-se a quantidade de $2,5 \mathrm{~kg} \mathrm{ha}^{-1}$ de sementes puras viáveis, com valor cultural (VC) de 32 e $28 \%$, respectivamente. Essas sementes foram misturadas ao adubo momentos antes da semeadura, acondicionadas no compartimento de fertilizante da semeadora e depositadas à profundidade de 8 e $6 \mathrm{~cm}$ para capim-marandu e capim-mombaça, respectivamente, que se localizaram, desta forma, abaixo da semente do sorgo, conforme recomendações de Kluthcouski et al. (2000). De modo geral, a emergência das plântulas de sorgo e dos capins ocorreu em 5 (capim-marandu) e 15 dias (capim-mombaça) após a semeadura.

A adubação mineral de semeadura de $\mathrm{P}$ e $\mathrm{K}$ feita conforme Cantarella et al. (1997) para sorgo granífero (250 $\mathrm{kg} \mathrm{ha}^{-1}$ da fórmula 0-20-10). Assim, para todos os tratamentos a quantidade aplicada de $\mathrm{P}_{2} \mathrm{O}_{5}$ e $\mathrm{K}_{2} \mathrm{O}$ foram iguais, tendo-se modificado somente a dose de $\mathrm{N}$, que foi aplicada manualmente. Trinta dias após a emergência do sorgo, procedeu-se à adubação mineral nitrogenada de cobertura, realizada por meio de adubador de cobertura para semeadura direta, com as doses referentes a cada tratamento.

No florescimento pleno das plantas de sorgo, foram realizadas as amostragens de folhas de 30 plantas por parcela, conforme Cantarella et al. (1997), para a determinação da diagnose foliar. As amostras foram posteriormente moídas e, em seguida, os teores de $\mathrm{N}, \mathrm{P}, \mathrm{K}, \mathrm{Ca}, \mathrm{Mg}$ e $\mathrm{S}$ foram determinados conforme Malavolta et al. (1997).

No momento da colheita mecânica do sorgo, em $23 / 6 / 2004$ e 29/4/2005, avaliaram-se as seguintes características agronômicas e produtivas: altura de planta, altura de inserção da panícula, diâmetro basal de colmo, produtividade de massa seca de colmos e folhas e número de grãos por panícula, em dez plantas por panículas, ao acaso por parcela; estande final de plantas e número de panículas por hectare, por contagem do número de plantas e panículas nas duas linhas centrais, em oito metros de fileira de cada parcela, extrapoladas posteriormente para hectare; a massa de mil grãos por coleta ao acaso e pesagem de oito amostras por parcela; e produtividade de grãos em quatro linhas centrais de cada parcela, tendo-se determinado a massa dos grãos colhidos, extrapoladas para quilograma por hectare, a $13 \%$ de umidade.

Após a colheita de grãos do sorgo, em agosto de 2004 e junho de 2005, realizou-se a avaliação da produtividade de massa seca da forragem (PMSF) do capim-marandu e capim-mombaça, tendo-se cortado a parte aérea das plantas (0,25 e 0,40 $\mathrm{m}$ da superfície do solo, respectivamente) com roçadora mecânica manual, em $2 \mathrm{~m}^{2}$ por parcela. O material coletado foi seco em estufa de circulação forçada de ar a $65^{\circ} \mathrm{C}$ por 72 horas e extrapolado, posteriormente, para quilograma por hectare.

Realizou-se análise de variância pelo teste $\mathrm{F}$ e comparação de médias pelo teste LSD, ambos a 5\% de probabilidade, com uso do Sisvar (Ferreira, 1999).

\section{Resultados e Discussão}

No ano agrícola 2003/2004, os maiores teores foliares de $\mathrm{K}$ foram verificados no cultivo solteiro, e não houve diferença entre os cultivos consorciados com o capim-marandu e o capim-mombaça (Tabela 1). Este

Tabela 1. Teores foliares $\left(\mathrm{g} \mathrm{kg}^{-1}\right)$ de nutrientes em sorgo granífero, em sistemas de cultivo solteiro e consorciado, com parcelamento de N (PN) na semeadura e cobertura, nos anos agrícolas 2003/2004 e 2004/2005 ${ }^{(1)}$.

\begin{tabular}{|c|c|c|c|c|c|c|c|c|c|c|c|c|}
\hline \multirow[t]{2}{*}{ Tratamento } & \multicolumn{6}{|c|}{$2003 / 2004$} & \multicolumn{6}{|c|}{$2004 / 2005$} \\
\hline & $\mathrm{N}$ & $\mathrm{P}$ & $\mathrm{K}$ & $\mathrm{Ca}$ & $\mathrm{Mg}$ & $\mathrm{S}$ & $\mathrm{N}$ & $\mathrm{P}$ & $\mathrm{K}$ & $\mathrm{Ca}$ & $\mathrm{Mg}$ & $\mathrm{S}$ \\
\hline \multicolumn{13}{|c|}{ Sistema de cultivo (SC) } \\
\hline Solteiro & $27,8 \mathrm{a}$ & $3,3 \mathrm{a}$ & $15,3 \mathrm{a}$ & $4,4 \mathrm{~b}$ & $-(2)$ & $2,0 \mathrm{a}$ & - & $4,6 b$ & $33,3 b$ & $8,3 \mathrm{ab}$ & $5,1 \mathrm{a}$ & - \\
\hline Marandu & $28,2 \mathrm{a}$ & $3,4 \mathrm{a}$ & $14,2 b$ & $7,8 \mathrm{~b}$ & - & $2,0 \mathrm{a}$ & - & $5,2 \mathrm{a}$ & $36,9 \mathrm{a}$ & $9,0 \mathrm{a}$ & $5,5 \mathrm{a}$ & - \\
\hline Mombaça & $28,6 \mathrm{a}$ & $3,3 \mathrm{a}$ & $14,5 \mathrm{~b}$ & $13,3 \mathrm{a}$ & - & $1,9 \mathrm{a}$ & - & $4,9 \mathrm{a}$ & $38,8 \mathrm{a}$ & $8,0 \mathrm{~b}$ & $5,6 \mathrm{a}$ & - \\
\hline \multicolumn{13}{|l|}{$\mathrm{PN}\left(\mathrm{kg} \mathrm{ha}^{-1}\right)^{(3)}$} \\
\hline $0-100$ & $29,4 \mathrm{a}$ & $3,2 \mathrm{a}$ & $14,9 \mathrm{a}$ & $6,9 \mathrm{a}$ & - & $2,1 \mathrm{a}$ & - & $4,6 b$ & $33,9 b$ & $8,3 \mathrm{a}$ & $5,4 \mathrm{a}$ & - \\
\hline $30-70$ & $28,6 \mathrm{ab}$ & $3,4 \mathrm{a}$ & $14,8 \mathrm{a}$ & $7,3 \mathrm{a}$ & - & $2,1 \mathrm{a}$ & - & $4,6 b$ & $37,3 \mathrm{ab}$ & $8,8 \mathrm{a}$ & $5,8 \mathrm{a}$ & - \\
\hline $50-50$ & $27,6 b$ & $3,4 \mathrm{a}$ & $14,1 \mathrm{a}$ & $6,8 \mathrm{a}$ & - & $1,9 b$ & - & $5,1 \mathrm{a}$ & $35,3 \mathrm{ab}$ & $8,3 \mathrm{a}$ & $5,5 \mathrm{a}$ & - \\
\hline $70-30$ & $27,1 b$ & $3,3 \mathrm{a}$ & $15,2 \mathrm{a}$ & $11,0 \mathrm{a}$ & - & $1,9 b$ & - & $5,0 \mathrm{ab}$ & $37,3 \mathrm{ab}$ & $8,1 \mathrm{a}$ & $5,3 a$ & - \\
\hline $100-0$ & $27,9 \mathrm{ab}$ & $3,2 \mathrm{a}$ & $14,3 \mathrm{a}$ & $10,4 \mathrm{a}$ & - & $2,0 \mathrm{ab}$ & - & $4,9 \mathrm{ab}$ & $37,9 a$ & $8,5 \mathrm{a}$ & $5,2 \mathrm{a}$ & - \\
\hline CV (\%) & 9,1 & 10,4 & 7,1 & 62,7 & 23,8 & 8,3 & 8,4 & 10,7 & 11,7 & 16,2 & 16,3 & 25,2 \\
\hline
\end{tabular}

${ }^{(1)}$ Médias seguidas de letras iguais, nas colunas, não diferem entre si, pelo teste LSD a 5\% de probabilidade. ${ }^{(2)}$ Interação significativa SC x PN. ${ }^{(3)}$ A primeira e a segunda doses referem-se ao $\mathrm{N}$ aplicado na semeadura e na cobertura, respectivamente. 
comportamento pode ser justificado pela alta demanda desse nutriente pelas forrageiras, o que estabeleceu uma competição pelo elemento. No entanto, em todos os tratamentos, os teores estavam no limite inferior da faixa considerada adequada para a cultura do sorgo granífero (Cantarella et al., 1997). Com relação ao teor foliar de $\mathrm{Ca}$, verificou-se maior valor no sistema de cultivo consorciado com o capim-mombaça. De acordo com Lange et al. (2006), o efeito depressivo nos teores de $\mathrm{Ca}$, em consequência da aplicação de $\mathrm{N}$, pode ser atribuído à maior produtividade de massa seca que favoreceu o efeito de diluição.

No ano agrícola 2003/2004, os maiores teores foliares de $\mathrm{N}$ foram verificados na aplicação de todo o $\mathrm{N}$ na cobertura (0-100 $\mathrm{kg} \mathrm{ha}^{-1}$ de $\left.\mathrm{N}\right)$, em relação aos parcelamentos 50-50 e 70-30 $\mathrm{kg} \mathrm{ha}^{-1}$ de N (Tabela 1). Para os teores foliares de $\mathrm{S}$, o maior valor foi verificado no parcelamento $30-70 \mathrm{~kg} \mathrm{ha}^{-1} \mathrm{deN}$, em comparação aos parcelamentos 50-50 e 70-30 $\mathrm{kg} \mathrm{ha}^{-1}$ de N. No entanto, apesar das diferenças verificadas entre os tratamentos, de maneira geral, o parcelamento da aplicação de $\mathrm{N}$ e o consórcio com os capins não teve efeito sobre o estado nutricional do sorgo granífero, uma vez que os teores estavam na faixa considerada adequada para a cultura (Cantarella et al., 1997), o que evidencia o efeito benéfico da rotação de culturas empregada por vários anos na área experimental que, em razão do grande aporte de material vegetal na superfície do solo, disponibilizou gradualmente os nutrientes para as plantas de sorgo granífero.

No ano agrícola 2004/2005, o maior teor foliar de $\mathrm{P}$ foi verificado nos cultivos consorciados com o capim-marandu e o capim-mombaça, bem como, no parcelamento $50-50 \mathrm{~kg} \mathrm{ha}^{-1}$ de $\mathrm{N}$, que foi superior aos parcelamentos $0-100$ e 30-70 $\mathrm{kg} \mathrm{ha}^{-1}$ de N (Tabela 1). De acordo com Silva et al. (2003), em solos cultivados com capim-marandu, verificam-se teores de P menores nas frações pouco lábeis e maiores nas frações mais lábeis, que favorecem a absorção do elemento pelas plantas. No entanto, em todos os tratamentos, os teores estavam na faixa adequada para a cultura do sorgo granífero (Cantarella et al., 1997). Segundo Anghinoni (2007), no SPD há maior disponibilidade de P atribuída ao não revolvimento do solo, o que reduz a fixação desse nutriente, e também atribuída à decomposição lenta e gradual da MO do solo, que o disponibiliza ao longo do ciclo da cultura.
No ano agrícola 2004/2005, o teor de K nos cultivos consorciados foi superior ao do cultivo solteiro, o que pode estar relacionado à capacidade de reciclagem desse nutriente pelas forrageiras (Tabela 1). Constatouse maior teor no parcelamento $100-0 \mathrm{~kg} \mathrm{ha}^{-1}$ de $\mathrm{N}$, que diferiu do tratamento $0-100 \mathrm{~kg} \mathrm{ha}^{-1}$ de N. No entanto, os teores foliares de $\mathrm{K}$ nesse ano foram bastante superiores aos verificados no ano anterior, tendo ficado inclusive acima dos teores considerados por Cantarella et al. (1997) como adequados para a cultura do sorgo granífero, o que demonstra que, a partir do segundo ano de cultivo, ocorreu liberação de $\mathrm{K}$ da palhada depositada na superfície do solo. Quanto ao Ca, no ano agrícola 2004/2005, verificou-se maior teor foliar no sorgo granífero em cultivo consorciado com o capim-marandu, em comparação ao sorgo granífero em consórcio com o capim-mombaça, e não houve efeito do parcelamento de nitrogênio.

Os teores foliares de $\mathrm{Mg}$, no ano agrícola 2003/2004, foram inferiores no cultivo consorciado com o capim-marandu nos parcelamentos 50-50 e 70-30 kg ha-1 de N (Tabela 2). Os teores foliares de $\mathrm{N}$ no ano agrícola 2004/2005, foram superiores

Tabela 2. Teores foliares $\left(\mathrm{g} \mathrm{kg}^{-1}\right)$ de $\mathrm{Mg}, \mathrm{N}$ e $\mathrm{S}$ em sorgo granífero, em sistemas de cultivo solteiro e consorciado, com parcelamento de $\mathrm{N}(\mathrm{PN})$ na semeadura e cobertura, nos anos agrícolas 2003/2004 e 2004/2005(1).

\begin{tabular}{cccc}
\hline Tratamento & \multicolumn{3}{c}{ Sistemas de cultivo } \\
\cline { 2 - 4 } & Solteiro & Marandu & Mombaça \\
\hline PN $\left(\mathrm{kg} \mathrm{ha}^{-1}\right)^{(2)}$ & & $\mathrm{Mg}(2003 / 2004)$ \\
$0-100$ & $4,8 \mathrm{Aa}$ & $4,8 \mathrm{Aa}$ & $4,7 \mathrm{Aa}$ \\
$30-70$ & $4,3 \mathrm{Aa}$ & $5,2 \mathrm{Aa}$ & $5,4 \mathrm{Aa}$ \\
$50-50$ & $4,9 \mathrm{Aa}$ & $3,1 \mathrm{Bb}$ & $5,5 \mathrm{Aa}$ \\
$70-30$ & $5,6 \mathrm{Aa}$ & $1,5 \mathrm{Bb}$ & $6,3 \mathrm{Aa}$ \\
$100-0$ & $5,3 \mathrm{Aa}$ & $6,0 \mathrm{Aa}$ & $5,4 \mathrm{Aa}$ \\
\hline & & $\mathrm{N}(2004 / 2005)$ \\
$0-100$ & $22,3 \mathrm{Ba}$ & $23,4 \mathrm{ABbc}$ & $25,6 \mathrm{Aa}$ \\
$30-70$ & $21,8 \mathrm{Aa}$ & $23,6 \mathrm{Aabc}$ & $23,3 \mathrm{Aab}$ \\
$50-50$ & $23,4 \mathrm{Ba}$ & $26,4 \mathrm{Aa}$ \\
$70-30$ & $23,1 \mathrm{Aa}$ & $20,1 \mathrm{Ac}$ & $21,2 \mathrm{Bb}$ \\
$100-0$ & $23,1 \mathrm{Aa}$ & $23,7 \mathrm{Aab}$ & $23,4 \mathrm{Aab}$ \\
& & $\mathrm{S}(2004 / 2005)$ \\
$0-100$ & $4,5 \mathrm{Aa}$ & $4,3 \mathrm{Aab}$ & \\
$30-70$ & $4,3 \mathrm{Bab}$ & $3,0 \mathrm{Bb}$ & $5,4 \mathrm{Aa}$ \\
$50-50$ & $3,8 \mathrm{Bab}$ & $3,9 \mathrm{Bab}$ & $6,8 \mathrm{Aa}$ \\
$70-30$ & $4,5 \mathrm{Bab}$ & $4,3 \mathrm{Bab}$ & $6,6 \mathrm{Aa}$ \\
$100-0$ & $2,7 \mathrm{Bb}$ & $5,5 \mathrm{Ba}$ & $6,5 \mathrm{Aa}$ \\
\hline
\end{tabular}

(1)Médias seguidas de letras iguais, maiúsculas nas linhas e minúsculas nas colunas, não diferem entre si, pelo teste LSD, a $5 \%$ de probabilidade.

${ }^{(2)}$ A primeira e a segunda doses referem-se ao $\mathrm{N}$ aplicado na semeadura e na cobertura, respetivamente. 
no cultivo com capim-mombaça, em comparação ao cultivo solteiro, no parcelamento $0-100 \mathrm{~kg} \mathrm{ha}^{-1}$ de N, e no cultivo com capim-marandu em comparação aos demais cultivos, no parcelamento $50-50 \mathrm{~kg} \mathrm{ha}^{-1}$ de N. Dentro dos sistemas de cultivo, no consórcio com capim-marandu, o parcelamento $50-50 \mathrm{~kg} \mathrm{ha}^{-1}$ de $\mathrm{N}$ foi superior aos parcelamentos $0-100$ e $70-30 \mathrm{~kg} \mathrm{ha}^{-1}$ de $\mathrm{N}$. No consórcio com capim-mombaça, o parcelamento $50-50 \mathrm{~kg} \mathrm{ha}^{-1}$ de $\mathrm{N}$ reduziu o teor foliar de $\mathrm{N}$ em relação ao parcelamento $0-100 \mathrm{~kg} \mathrm{ha}^{-1}$ de $\mathrm{N}$, e esse último foi o único que atingiu o teor na faixa de $25-35 \mathrm{~g} \mathrm{~kg}^{-1}$, considerado por Cantarella et al. (1997) como adequado para a cultura do sorgo granífero. Isso mostra que, apesar da adubação nitrogenada, no segundo ano de cultivo a palhada depositada na superfície do solo pode ter imobilizado parte do $\mathrm{N}$ aplicado.

Quanto ao teor foliar de S, no ano agrícola 2004/2005, com exceção do parcelamento $0-100 \mathrm{~kg} \mathrm{ha}^{-1}$ de N, o consórcio com capim-mombaça apresentou os maiores valores (Tabela 2). No cultivo solteiro, o parcelamento $100-0 \mathrm{~kg} \mathrm{ha}^{-1}$ de N reduziu esse teor em comparação ao de $0-100 \mathrm{~kg} \mathrm{ha}^{-1}$ de $\mathrm{N}$ e, no cultivo com capim-marandu, o parcelamento $30-70 \mathrm{~kg} \mathrm{ha}^{-1}$ de $\mathrm{N}$ reduziu esse teor em comparação ao de $100-0 \mathrm{~kg} \mathrm{ha}^{-1}$ de N. Contudo, os teores foliares desse nutriente encontraram-se na faixa adequada para o desenvolvimento da cultura (Cantarella et al., 1997) e foram superiores aos verificados no ano agrícola 2003/2004. Lange et al. (2006) atribuem tal efeito à mineralização dos resíduos vegetais que estavam sobre o solo, que aumentaram a disponibilidade de S. Esses autores também destacam que o aumento da ocorrência de solos deficientes em $\mathrm{S}$ é atribuída à falta de reposição desse nutriente exportado pelos grãos, visto que, para a mineralização do $\mathrm{S}$, é preciso uma adequada relação $\mathrm{C} / \mathrm{S}$ na $\mathrm{MO}$, o que é difícil em palhada de forrageiras tropicais com alta relação $\mathrm{C} / \mathrm{N}$, utilizadas no sistema de semeadura direta.

No dois anos agrícolas, o diâmetro basal de colmo (DBC) das plantas de sorgo granífero, no cultivo consorciado com capim-mombaça, foi superior àquele com capim-marandu, e foi também superior ao cultivo solteiro (Tabela 3 ). O parcelamento 70 $30 \mathrm{~kg} \mathrm{ha}^{-1}$ de $\mathrm{N}$ reduziu esse atributo em relação aos parcelamentos $0-100$ e $30-70 \mathrm{~kg} \mathrm{ha}^{-1}$ de N. Após a colheita de grãos, os restos culturais do sorgo reciclam parte dos nutrientes no solo, principalmente $\mathrm{K}$, Ca e Mg contidos na palhada (Coelho et al., 2002). Assim, possivelmente, a maior disponibilidade e, conseqüentemente, a melhor nutrição com $\mathrm{K}$ no segundo ano de cultivo, em relação ao primeiro ano (Tabela 1), aumentou o DBC, pois a deficiência desse nutriente proporciona colmos mais finos nas culturas do milho e sorgo granífero (Malavolta et al., 1997). Vale ressaltar que plantas com colmos mais finos têm menor capacidade de translocação de água e nutrientes, e são mais susceptíveis ao acamamento. Apesar de não ocorrer diferença significativa entre os tratamentos, no segundo ano de cultivo verificaram plantas com menor altura, que também são menos propícias ao acamamento, principalmente pelo efeito do vento, que é bastante agravante na região em estudo.

Tabela 3. Altura de plantas (AP, m), altura de inserção da panícula (AIP, m), diâmetro basal de colmo (DBC, mm) e produtividade de matéria seca (PMS, $\mathrm{kg} \mathrm{ha}^{-1}$ ) do sorgo granífero, em sistemas de cultivo solteiro e consorciado, com parcelamento de N (PN) na semeadura e cobertura, nos anos agrícolas 2003/2004 e 2004/2005 ${ }^{(1)}$.

\begin{tabular}{|c|c|c|c|c|c|c|c|c|}
\hline \multirow[t]{2}{*}{ Tratamento } & \multicolumn{4}{|c|}{$2003 / 2004$} & \multicolumn{4}{|c|}{$2004 / 2005$} \\
\hline & $\mathrm{AP}$ & AIP & DBC & PMS & $\mathrm{AP}$ & AIP & DBC & PMS \\
\hline \multicolumn{9}{|c|}{ Sistema de cultivo (SC) } \\
\hline Solteiro & $1,45 \mathrm{a}$ & $-(2)$ & $11,70 \mathrm{ab}$ & $3.146 \mathrm{a}$ & $1,32 \mathrm{a}$ & $1,08 \mathrm{a}$ & $16,7 b$ & $3.215 \mathrm{a}$ \\
\hline Marandu & $1,65 \mathrm{a}$ & - & $11,50 \mathrm{~b}$ & $3.249 \mathrm{a}$ & $1,29 \mathrm{a}$ & $1,05 \mathrm{a}$ & $17,1 \mathrm{~b}$ & $3.358 \mathrm{a}$ \\
\hline Mombaça & $1,60 \mathrm{a}$ & - & $12,65 \mathrm{a}$ & $3.146 \mathrm{a}$ & $1,31 \mathrm{a}$ & $1,06 \mathrm{a}$ & $18,3 \mathrm{a}$ & $3.643 \mathrm{a}$ \\
\hline \multicolumn{9}{|l|}{$\overline{\mathrm{PN}}\left(\mathrm{kg} \mathrm{ha}{ }^{-1}\right)^{(3)}$} \\
\hline $0-100$ & $1,58 \mathrm{a}$ & - & $11,42 \mathrm{a}$ & $3.243 \mathrm{a}$ & $1,31 \mathrm{a}$ & $1,06 \mathrm{a}$ & $20,0 \mathrm{a}$ & $3.398 \mathrm{ab}$ \\
\hline $30-70$ & $1,75 \mathrm{a}$ & - & $11,92 \mathrm{a}$ & $3.281 \mathrm{a}$ & $1,33 \mathrm{a}$ & $1,09 \mathrm{a}$ & $17,8 \mathrm{a}$ & $3.256 \mathrm{~b}$ \\
\hline $50-50$ & $1,42 \mathrm{a}$ & - & $12,08 \mathrm{a}$ & $2.985 \mathrm{a}$ & $1,31 \mathrm{a}$ & $1,06 \mathrm{a}$ & $17,2 \mathrm{ab}$ & $3.342 \mathrm{ab}$ \\
\hline $70-30$ & $1,50 \mathrm{a}$ & - & $12,92 \mathrm{a}$ & $3.523 \mathrm{a}$ & $1,29 \mathrm{a}$ & $1,06 \mathrm{a}$ & $16,2 \mathrm{~b}$ & $3.994 \mathrm{a}$ \\
\hline $100-0$ & $1,58 \mathrm{a}$ & - & $11,42 \mathrm{a}$ & $3.354 \mathrm{a}$ & $1,28 \mathrm{a}$ & $1,04 \mathrm{a}$ & $17,6 \mathrm{ab}$ & $3.035 \mathrm{~b}$ \\
\hline$\overline{\mathrm{CV}(\%)}$ & 30,5 & 7,2 & 14,3 & 33,3 & 7,4 & 5,4 & 10,9 & 24,8 \\
\hline
\end{tabular}


Apenas no ano agrícola 2004/2005, a produtividade de matéria seca (PMS) do sorgo granífero foi reduzida nos parcelamentos 30-70 e 100-0 $\mathrm{kg} \mathrm{ha}^{-1}$ de $\mathrm{N}$, em comparação ao parcelamento $70-30 \mathrm{~kg}^{-1} \mathrm{ha}^{-1}$ de $\mathrm{N}$ (Tabela 3). Tais resultados podem ser explicados pela máxima absorção de $\mathrm{N}$ e $\mathrm{P}$ durante as fases de desenvolvimento vegetativo e formação dos grãos, e menor absorção desses nutrientes no período compreendido entre a emissão da panícula e o início da formação dos grãos, em que os nutrientes são, quase totalmente, translocados para os grãos (Coelho et al., 2002).

O parcelamento $0-100 \mathrm{~kg} \mathrm{ha}^{-1}$ de $\mathrm{N}$, no cultivo solteiro do ano agrícola 2003/2004, aumentou a altura de inserção da panícula (AIP) (Tabela 4), em comparação aos consórcios com capim-marandu e capim-mombaça,

Tabela 4. Altura de inserção da panícula $(\mathrm{m})$ do sorgo granífero, em sistema de cultivo solteiro e consorciado, com parcelamento de $\mathrm{N}(\mathrm{PN})$ na semeadura e cobertura, no ano agrícola $2003 / 2004^{(1)}$.

\begin{tabular}{cccc}
\hline Tratamento & \multicolumn{3}{c}{ Sistemas de cultivo } \\
\cline { 2 - 4 } & Solteiro & Marandu & Mombaça \\
\hline PN $\left(\mathrm{kg} \mathrm{ha}^{-1}\right)^{(2)}$ & & & \\
$0-100$ & $1,23 \mathrm{Aa}$ & $1,00 \mathrm{Ba}$ & $1,00 \mathrm{Ba}$ \\
$30-70$ & $1,09 \mathrm{Ab}$ & $1,00 \mathrm{Aa}$ & $1,00 \mathrm{Aa}$ \\
$50-50$ & $1,00 \mathrm{Ab}$ & $1,00 \mathrm{Aa}$ & $1,00 \mathrm{Aa}$ \\
$70-30$ & $1,00 \mathrm{Ab}$ & $1,00 \mathrm{Aa}$ & $1,00 \mathrm{Aa}$ \\
$100-0$ & $1,00 \mathrm{Ab}$ & $1,00 \mathrm{Aa}$ & $1,00 \mathrm{Aa}$ \\
\hline
\end{tabular}

(1)Médias seguidas de letras iguais, maiúsculas nas linhas e minúsculas nas colunas, não diferem entre si, pelo teste LSD a 5\% de probabilidade. ${ }^{(2)} \mathrm{A}$ primeira e segunda doses referem-se ao $\mathrm{N}$ aplicado na semeadura e na cobertura, respectivamente. o que mostra que, em consórcio, a competição por $\mathrm{N}$ inibiu a AIP. Os demais resultados, inclusive do ano agrícola 2003/2004 (Tabela 3), mostraram que a homogeneidade da AIP é uma característica peculiar do híbrido utilizado. Vale ressaltar que a maior AIP aliada à homogeneidade dessa característica favorece a colheita mecanizada, o que diminui as perdas de panículas não colhidas pela plataforma da colhedora.

$\mathrm{O}$ estande final de plantas (EFP) e o número de panículas por hectare (NPha) não foram influenciados pelos tratamentos nos dois anos agrícolas (Tabela 5). $\mathrm{O}$ número de grãos por panícula (NGP) foi superior apenas no parcelamento $100-0 \mathrm{~kg} \mathrm{ha}^{-1} \mathrm{de} \mathrm{N}$, no segundo ano de cultivo, o que mostra que a aplicação de todo o $\mathrm{N}$ na semeadura elevou o NGP. No primeiro ano de cultivo, o parcelamento $50-50 \mathrm{~kg} \mathrm{ha}^{-1}$ de $\mathrm{N}$ aumentou a produtividade de grãos $(\mathrm{PG})$, em comparação aos parcelamentos $0-100,30-70$ e 70-30 $\mathrm{kg} \mathrm{ha}^{-1}$ de N. No segundo ano, não houve efeito dos tratamentos no PG que, no entanto, foram inferiores às verificadas no ano agrícola anterior. Isto mostra que os efeitos sinérgicos entre o NPha, o NGP e a massa de mil grãos (MMG) são os principais atributos relacionados ao PG da cultura do sorgo, já que no presente trabalho a diminuição do NPha diminuiu a PG.

De acordo com Machado (2007), é necessário conhecer a influência que os resíduos dessecados do capim podem exercer na cultura subsequente. O capim-marandu e o capim-mombaça são extremamente produtivos em solos de alta fertilidade e são de difícil erradicação com herbicidas,

Tabela 5. Estande final de plantas (EFP, plantas ha ${ }^{-1}$ ), número de panículas por hectare (NPha), número de grãos por panícula (NGP), massa de mil grãos (MMG, g) e produtividade de grãos ( $\left.\mathrm{PG}, \mathrm{kg} \mathrm{ha}^{-1}\right)$ do sorgo granífero, em sistemas de cultivo solteiro e consorciado, com parcelamento de N (PN) na semeadura e cobertura, nos anos agrícolas 2003/2004 e 2004/2005 ${ }^{(1)}$.

\begin{tabular}{|c|c|c|c|c|c|c|c|c|c|c|}
\hline \multirow[t]{2}{*}{ Tratamento } & \multicolumn{5}{|c|}{$2003 / 2004$} & \multicolumn{5}{|c|}{$2004 / 2005$} \\
\hline & EFP & NPha & NGP & MMG & PG & EFP & NPha & NGP & MMG & PG \\
\hline \multicolumn{11}{|c|}{ Sistema de cultivo (SC) } \\
\hline Solteiro & $192.444 \mathrm{a}$ & $161.653 \mathrm{a}$ & $1.248 \mathrm{a}$ & $-(2)$ & $4.115 \mathrm{a}$ & $122.000 \mathrm{a}$ & $103.000 \mathrm{a}$ & $1.312 \mathrm{a}$ & - & $2.482 \mathrm{a}$ \\
\hline Marandu & $178.889 a$ & $148.478 \mathrm{a}$ & $1.129 \mathrm{a}$ & - & $4.168 \mathrm{a}$ & $132.750 \mathrm{a}$ & $107.750 \mathrm{a}$ & $1.209 \mathrm{a}$ & - & $2.617 \mathrm{a}$ \\
\hline Mombaça & $178.889 \mathrm{a}$ & $146.689 \mathrm{a}$ & $1.284 \mathrm{a}$ & - & $3.916 \mathrm{a}$ & $133.124 \mathrm{a}$ & $107.000 \mathrm{a}$ & $1.431 \mathrm{a}$ & - & $2.719 \mathrm{a}$ \\
\hline \multicolumn{11}{|l|}{$\overline{\mathrm{PN}}\left(\mathrm{kg} \mathrm{ha}^{-1}\right)^{(3)}$} \\
\hline $0-100$ & $172.222 \mathrm{a}$ & $142.944 \mathrm{a}$ & $1.149 \mathrm{a}$ & - & $3.809 \mathrm{~b}$ & $137.708 \mathrm{a}$ & $102.604 a$ & $1.235 \mathrm{~b}$ & - & $2.526 \mathrm{a}$ \\
\hline $30-70$ & $197.407 \mathrm{a}$ & $161.874 \mathrm{a}$ & $1.154 \mathrm{a}$ & - & $3.859 \mathrm{~b}$ & $131.876 \mathrm{a}$ & $116.667 \mathrm{a}$ & $1.269 \mathrm{~b}$ & - & $2.719 \mathrm{a}$ \\
\hline $50-50$ & $189.259 \mathrm{a}$ & $158.978 \mathrm{a}$ & $1.236 \mathrm{a}$ & - & $4.590 \mathrm{a}$ & $130.416 \mathrm{a}$ & $102.917 \mathrm{a}$ & $1.224 \mathrm{~b}$ & - & $2.500 \mathrm{a}$ \\
\hline $70-30$ & $188.518 \mathrm{a}$ & $156.470 \mathrm{a}$ & $1.380 \mathrm{a}$ & - & $3.925 \mathrm{~b}$ & $120.000 \mathrm{a}$ & $113.542 \mathrm{a}$ & $1.251 \mathrm{~b}$ & - & $2.805 \mathrm{a}$ \\
\hline $100-0$ & $169.629 a$ & $142.488 \mathrm{a}$ & $1.181 \mathrm{a}$ & - & $4.148 \mathrm{ab}$ & $126.458 \mathrm{a}$ & $93.854 a$ & $1.608 \mathrm{a}$ & - & $2.481 \mathrm{a}$ \\
\hline CV (\%) & 19,9 & 30,3 & 28,7 & 6,6 & 16,6 & 14,5 & 27,2 & 26,9 & 9,9 & 29,2 \\
\hline
\end{tabular}

${ }^{(1)}$ Médias seguidas de letras iguais, nas colunas, não diferem entre si, pelo teste LSD, a $5 \%$ de probabilidade. ${ }^{(2)}$ Interação significativa SC x PN. ${ }^{(3)} \mathrm{A}$ primeira e segunda doses referem-se ao $\mathrm{N}$ aplicado na semeadura e na cobertura, respectivamente. 
principalmente, quando degradados ou com deficiência de N. Para a dessecação da pastagem e retorno de cultura granífera na área, o capim precisa apresentar área foliar suficiente para assimilação de herbicidas e um prazo de aproximadamente 20 dias para o início da semeadura.

Visto que o EFP também diminuiu no segundo ano de cultivo (Tabela 5), a grande deposição de palhada sobre o solo, após o manejo dos capins provenientes dos consórcios instalados no ano agrícola anterior (2003/2004) pode afetar o estabelecimento do sorgo quando semeado em sucessão. Borghi (2007) também verificou isto, enquanto Pariz (2011) minimizou esse efeito em cultura do milho sobre a palhada, pelo manejo mecânico dos capins com um triturador de resíduos vegetais após a dessecação química.

A maior disponibilidade de nutrientes, possivelmente, contribuiu para o aumento da MMG no segundo ano de cultivo (Tabela 6). No entanto, esse aumento não se refletiu em maior PG. No ano agrícola 2003/2004, o cultivo consorciado com capim-marandu elevou a MMG em comparação aos demais sistemas de cultivo no parcelamento $100-0 \mathrm{~kg}^{-1}$ de $\mathrm{N}$, enquanto no ano agrícola 2004/2005 essa elevação foi verificada no cultivo solteiro, no parcelamento 30-70 $\mathrm{kg} \mathrm{ha}^{-1}$ de $\mathrm{N}$, e no cultivo consorciado com capim-marandu no parcelamento $100-0 \mathrm{~kg} \mathrm{ha}^{-1} \mathrm{de}$ N. Da mesma forma, no ano agrícola 2003/2004, o

Tabela 6. Massa de mil grãos (g) de sorgo granífero, em sistemas de cultivo solteiro e consorciado, com parcelamento de $\mathrm{N}(\mathrm{PN})$ na semeadura e cobertura, nos anos agrícolas $2003 / 2004$ e $2004 / 2005^{(1)}$.

\begin{tabular}{cccc}
\hline Tratamenro & \multicolumn{3}{c}{ Sistema de cultivo } \\
\cline { 2 - 4 } & Solteiro & Marandu & Mombaça \\
\hline PN $\left(\mathrm{kg} \mathrm{ha}^{-1}\right)^{(2)}$ & & $2003 / 2004$ \\
$0-100$ & $14,3 \mathrm{Ab}$ & $14,8 \mathrm{Ab}$ & $14,8 \mathrm{Aa}$ \\
$30-70$ & $15,1 \mathrm{Ab}$ & $14,5 \mathrm{Ab}$ & $14,5 \mathrm{Aa}$ \\
$50-50$ & $14,5 \mathrm{Ab}$ & $15,0 \mathrm{Ab}$ & $15,3 \mathrm{Aa}$ \\
$70-30$ & $14,8 \mathrm{Ab}$ & $15,0 \mathrm{Ab}$ & $14,5 \mathrm{Aa}$ \\
$100-0$ & $16,8 \mathrm{Ba}$ & $18,3 \mathrm{Aa}$ & $15,3 \mathrm{Ca}$ \\
\hline & & $2004 / 2005$ \\
$0-100$ & $25,2 \mathrm{Aa}$ & $26,9 \mathrm{Aa}$ & $24,7 \mathrm{Ab}$ \\
$30-70$ & $27,1 \mathrm{Aa}$ & $23,4 \mathrm{Bb}$ & $23,3 \mathrm{Bbc}$ \\
$50-50$ & $25,1 \mathrm{Aa}$ & $25,3 \mathrm{Aab}$ & $27,5 \mathrm{Aa}$ \\
$70-30$ & $25,8 \mathrm{Aa}$ & $23,2 \mathrm{Ab}$ & $22,4 \mathrm{Abc}$ \\
$100-0$ & $25,9 \mathrm{Aa}$ & $26,7 \mathrm{Aab}$ & $20,3 \mathrm{Bc}$ \\
\hline
\end{tabular}

${ }^{(1)}$ Médias seguidas de letras iguais, maiúsculas nas linhas e minúsculas nas colunas, não diferem entre si, pelo teste LSD a $5 \%$ de probabilidade. ${ }^{(2)}$ A primeira e a segunda doses referem-se ao $\mathrm{N}$ aplicado na semeadura e na cobertura, respectivamente parcelamento $100-0 \mathrm{~kg} \mathrm{ha}^{-1}$ de $\mathrm{N}$ aumentou a $\mathrm{MMG}$ nos cultivos solteiro e consorciado com capim-marandu e, no ano seguinte, diminuiu nos parcelamentos 30-70 e 70-30 kg ha-1 de N, em comparação ao parcelamento 0-100 kg ha-1 de N, no consórcio com capim-marandu, e aumentou no parcelamento $50-50 \mathrm{~kg} \mathrm{ha}^{-1}$ de $\mathrm{N}$ no consórcio com capim-mombaça. Assim, a MMG foi influenciada diferentemente entre os sistemas, anos de cultivo e parcelamento de nitrogênio

De maneira geral, a falta de resposta de alguns parâmetros ao parcelamento de N pode ser explicada pelo período de cultivo da área em SPD, com rotação de culturas que proporcionaram manutenção permanente da cobertura do solo. Além disso, a dessecação de plantas jovens de milheto, antes da implantação do experimento, aliada à rápida decomposição desse resíduo, disponibilizaram grande quantidade de $\mathrm{N}$ que não foi limitante para desenvolvimento das plantas de sorgo.

No primeiro ano agrícola, a produtividade de matéria seca da forragem (PMSF) do capim-marandu e do capim-mombaça, após a colheita do sorgo, não foi influenciada pela interação entre sistema de cultivo e parcelamento de $\mathrm{N}$ ou pelo efeito isolado dos fatores (Tabela 7). No entanto, as PMSF acima de $3 \mathrm{Mg} \mathrm{ha}^{-1}$ podem ser consideradas satisfatórias para a época da avaliação (agosto), aproximadamente 60 dias após a colheita do sorgo. Vale ressaltar que foi possível

Tabela 7. Produtividade de matéria seca da forragem $(\mathrm{kg}$ ha $^{-1}$ ) dos capim-marandu e capim-mombaça, após sistema de cultivo consorciado com sorgo granífero, com parcelamento de $\mathrm{N}(\mathrm{PN})$ na semeadura e cobertura, nos anos agrícolas $2003 / 2004$ e $2004 / 2005^{(1)}$.

\begin{tabular}{|c|c|c|c|}
\hline \multirow{2}{*}{$\begin{array}{l}\text { Tratamento } \\
\text { Sistema de cultivo }(\mathrm{SC})^{(2)}\end{array}$} & \multirow[t]{2}{*}{$2003 / 2004$} & \multicolumn{2}{|c|}{$2004 / 2005$} \\
\hline & & Marandu & Mombaça \\
\hline Marandu & $3.674 \mathrm{a}$ & - & - \\
\hline Mombaça & $3.742 \mathrm{a}$ & - & - \\
\hline \multicolumn{4}{|l|}{$\mathrm{PN}\left(\mathrm{kg} \mathrm{ha}^{-1}\right)^{(3)}$} \\
\hline $0-100$ & $4.364 \mathrm{a}$ & $4.084 \mathrm{Ab}$ & $1.391 \mathrm{Bc}$ \\
\hline $30-70$ & $3.928 \mathrm{a}$ & $2.117 \mathrm{Ac}$ & $1.124 \mathrm{Bc}$ \\
\hline $50-50$ & $3.119 \mathrm{a}$ & 5.957Aa & $2.807 \mathrm{Bb}$ \\
\hline $70-30$ & $4.248 \mathrm{a}$ & $1.900 \mathrm{Bc}$ & $2.422 \mathrm{Ab}$ \\
\hline $100-0$ & $3.220 \mathrm{a}$ & $1.853 \mathrm{Bc}$ & $3.624 \mathrm{Aa}$ \\
\hline$\overline{\mathrm{CV}(\%)}$ & 30,15 & \multicolumn{2}{|c|}{15,0} \\
\hline \multicolumn{4}{|c|}{$\begin{array}{l}\text { (1)Médias seguidas de letras iguais, maiúsculas nas linhas e minúsculas nas } \\
\text { colunas, dentro de cada ano agrícola, não diferem entre si, pelo teste LSD, } \\
\text { a } 5 \% \text { de probabilidade. }{ }^{\left({ }^{2}\right)} \text { Média de todos os parcelamentos de } \mathrm{N} \text { em cada } \\
\text { capim. }{ }^{(3)} \text { Média de ambos os capins, dentro de cada parcelamento de N. } \\
\text { A primeira e a segunda doses referem-se ao } \mathrm{N} \text { aplicado na semeadura e na } \\
\text { cobertura, respectivamente. }\end{array}$} \\
\hline
\end{tabular}

Pesq. agropec. bras., Brasília, v.46, n.10, p.1161-1169, out. 2011 
apenas um corte dos capins, já que a colheita do sorgo ocorreu no início do inverno e, em outubro, o capim foi dessecado para formação de palhada e semeadura das culturas para avaliação do segundo ano agrícola. No segundo ano, foi realizado apenas um corte dos capins no mês de junho, visto que após este corte, a baixa precipitação pluvial e a ocorrência de temperaturas abaixo de $15^{\circ} \mathrm{C}$ foram limitantes para o crescimento dessas gramíneas (Müller et al., 2002). No entanto, possivelmente em razão da semeadura no início da primavera e colheita de grãos no início do outono, o aproveitamento do $\mathrm{N}$ pelo capim foi diferente do verificado no ano agrícola anterior.

Nos parcelamentos 0-100, 30-70 e 50-50 kg ha-1 de $\mathrm{N}$, o capim-marandu foi mais produtivo, enquanto nos parcelamentos 70-30 e 100-0 $\mathrm{kg} \mathrm{ha}^{-1}$ de $\mathrm{N}$, o capim-mombaça apresentou maior PMSF (Tabela 7). Entre os sistemas de cultivo, a maior PMSF do capim-marandu ocorreu no parcelamento $50-50 \mathrm{~kg}$ $\mathrm{ha}^{-1}$ de $\mathrm{N}$ e a do capim-mombaça no parcelamento 100-0 kg ha-1 de $\mathrm{N}$, seguido dos parcelamentos 50-50, 70-30 e 0-100, 30-70 kg ha- de $\mathrm{N}$. Assim, o capim-mombaça foi mais eficiente no aproveitamento do $\mathrm{N}$, quando a maior quantidade de aplicação deste ocorreu na semeadura, o que mostra sua grande capacidade inicial de competição por nutrientes quando está em consórcio com o sorgo granífero. O capim-marandu não foi tão competitivo inicialmente e teve melhor aproveitamento do $\mathrm{N}$ aplicado em cobertura no consórcio, principalmente nos parcelamentos $0-100$ e $50-50 \mathrm{~kg} \mathrm{ha}^{-1}$ de $\mathrm{N}$, visto que no parcelamento $30-70 \mathrm{~kg} \mathrm{ha}^{-1}$ de $\mathrm{N}$, pela menor aplicação do nutriente à semeadura, a cultura do sorgo, possivelmente, ainda competiu por certa quantidade aplicada em cobertura.

\section{Conclusões}

1. A consorciação com o capim-marandu e o capim-mombaça não afeta a nutrição e a produtividade de grãos do sorgo.

2. No primeiro ano de cultivo, o parcelamento $50-50 \mathrm{~kg} \mathrm{ha}^{-1}$ de $\mathrm{N}$ proporciona maior produtividade de grãos do sorgo.

3. No segundo ano de cultivo, o parcelamento do $\mathrm{N}$ não altera a produtividade de grãos; no entanto, $\mathrm{o}$ manejo do capim para formação da palhada interfere no estabelecimento da cultura do sorgo e diminui a produtividade de grãos.
4. Após a colheita do sorgo, as maiores doses de $\mathrm{N}$ aplicadas em cobertura no consórcio, elevam a produtividade de matéria seca da forragem do capim-marandu, e as maiores doses de $\mathrm{N}$, aplicadas em semeadura, a elevam no capim-mombaça.

\section{Agradecimentos}

À Fundação de Amparo à Pesquisa do Estado de São Paulo, pelo financiamento da pesquisa; e ao Conselho Nacional de Desenvolvimento Científico e Tecnológico, por concessão de bolsa de produtividade em pesquisa ao segundo e quinto autores.

\section{Referências}

ALlEN, V.G.; BAKER, M.T.; SEGARRA, E.; BROWN, C.P. Integrated irrigated crop-livestock systems in dry climates. Agronomy Journal, v.99, p.346-360, 2007.

ANGHINONI, I. Fertilidade do solo e seu manejo em sistema plantio direto. In: NOVAIS, R.F.; ALVARES V., V.H.; BARROS, N.F. de; FONTES, R.L.F.; CANTARUTTI, R.B.; NEVES, J.C.L. (Ed.). Fertilidade do solo. Viçosa: Sociedade Brasileira de Ciência do Solo, 2007. p.873-928.

BALBINOT JÚNIOR, A.A.; MORAES, A. de; VEIGA, M. da; PELISSARI, A.; DIECKOW, J. Integração lavoura-pecuária: intensificação de uso de áreas agrícolas. Ciência Rural, v.39, p.1925-1933, 2009.

BORGHI, E. Produção de milho e capins 'Marandu' e 'Mombaça' em função de modos de implantação do consórcio. 2007. 142p. Tese (Doutorado) - Universidade Estadual Paulista, Botucatu.

CANTARELLA, H.; RAIJ, B. van.; CAMARGO, C.E.O. Cereais. In: RAIJ, B. van.; CANTARELLA, H.; QUAGGIO, J.A.; FURLANI, A.M.C. Recomendação de adubação e calagem para o Estado de São Paulo. 2.ed. rev. atual. Campinas: Instituto Agronômico, 1997. p.43-71. (IAC. Boletim técnico, 100).

CARVALHO, P.C. de F.; ANGHINONI, I.; MORAES, A. de; SOUZA, E.D. de; SULC, R.M.; LANG, C.R.; FLORES, J.P.C.; LOPES, M.L.T.; SILVA, J.L.S. da; CONTE, O.; WESP, C.L.; LEVIEN, R.; FONTANELI, R.S.; BAYER, C. Managing grazing animals to achieve nutrient cycling and soil improvement in no-till integrated systems. Nutrient Cycling in Agroecosystems, v.88, p.259-273, 2010.

COELHO, A.M.; WAQUIL, J.M.; KARAM, D.; CASELA, C.R.; RIBAS, P.M. Seja o doutor do seu sorgo. Informações Agronômicas, n.100, p.1-12, 2002. Encarte.

FERREIRA, D.F. SISVAR: sistema de análise de variância. Lavras: UFLA, 1999.

JAKELAITIS, A.; SILVA, A.F.; SILVA, A.A.; FERREIRA, L.R.; FREITAS, F.C.L; VIANA, R.G. Influência de herbicidas e de sistemas de semeadura de Brachiaria brizantha consorciada com milho. Planta Daninha, v.23, p.59-67, 2005. 
KLUTHCOUSKI, J.; COBUCCI, T.; AIDAR, H.; YOKOYAMA, L.P.; OLIVEIRA, I.P. de. COSTA, J.L. da S.; SILVA, J.G. da; VILELA, L.; BACELLOS, A. de O.; MAGNABOSCO, C. de U. Sistema Santa Fé: tecnologia Embrapa: integração lavoura-pecuária pelo consórcio de culturas anuais com forrageiras, em áreas de lavoura, nos sistemas plantio direto e convencional. Santo Antonio de Goiás: Embrapa Arroz e Feijão, 2000. 28p. (Circular técnica, 38).

LANGE, A.; CARVALHO, J.L.N.; DAMIN, V.; CRUZ, J.C.; GUILHERME, L.R.G.; MARQUES, J.J. Doses de nitrogênio e de palha em sistema plantio direto de milho no Cerrado. Revista Ceres, v.53, p.171-178, 2006.

MACEDO, M.C.M.M. Integração lavoura e pecuária: o estado da arte e inovações tecnológicas. Revista Brasileira de Zootecnia, v.38, p.133-146, 2009. Suplemento.

MACHADO, L.A.Z. Produção animal em sistemas integrados de agricultura e pecuária. In: SIMPÓSIO SOBRE MANEJO DA PASTAGEM, 24, 2007, Piracicaba. Produção de ruminantes em pastagens: anais. Piracicaba: FEALQ, 2007. p.227-242.

MALAVOLTA, E.; VITTI, G.C.; OLIVEIRA, S.A. de. Avaliação do estado nutricional das plantas: princípios e aplicações. 2.ed. Piracicaba: Associação Brasileira para Pesquisa da Potassa e do Fosfato, 1997. 319p.

MÜLLER, M. dos S.; FANCELLI, A.L.; DOURADO-NETO, D.; GARCÍA y GARCÍA, A.; LÓPEZ OVEJERO, R.F. Produtividade do Panicum maximum cv. Mombaça irrigado, sob pastejo rotacionado. Scientia Agricola, v.59, p.427-433, 2002.

PARIZ, C.M.; ANDREOTTI, M.; BERGAMASCHINE, A.F.; BUZETTI, S.; COSTA, N.R.; CAVALLINI, M.C.; ULIAN, N.A.; LUIGGI, F.G. Yield chemical composition and chlorophyll relative content of Tanzania and Mombaça grasses irrigated and fertilized with nitrogen after corn intercropping. Revista Brasileira de Zootecnia, v.40, p.728-738, 2011.

ROSOLEM, C.A.; MACHADO, J.R.; BRINHOLI, O. Efeito de adubação nitrogenada, fosfatada e potássica no sorgo sacarino em um Latossolo Roxo. Pesquisa Agropecuária Brasileira, v.20, p.635-641, 1985 .

SANTOS, H.G. dos; JACOMINE, P.K.T.; ANJOS, L.H.C. dos; OLIVEIRA, V.A. de; OLIVEIRA, J.B. de; COELHO, M.R.; LUMBRERAS, J.F.; CUNHA, T.J.F. (Ed.). Sistema brasileiro de classificação de solos. 2.ed. Rio de Janeiro: Embrapa Solos, 2006. $306 \mathrm{p}$.

SILVA, M.A. da; NÓBREGA, J.C.A.; CURI, N.; SIQUEIRA, J.O.; MARQUES, J.J.G. de M.; MOTTA, P.E.F. Frações de fósforo em Latossolos. Pesquisa Agropecuária Brasileira, v.38, p.1197-1207, 2003.

TRACY, B.F.; ZHANG, Y. Soil compaction, corn yield response, and soil nutrient pool dynamics within an integrated crop-livestock system in Illinois. Crop Science, v.48, p.1211-1218, 2008.

Recebido em 29 de junho de 2010 e aprovado em 18 de agosto de 2011 